\title{
The guiding logics and principles for designing emergent transdisciplinary research processes: learning experiences and reflections from a transdisciplinary urban case study in Enkanini informal settlement, South Africa
}

\author{
John van Breda ${ }^{1}\left[\right.$ Mark Swilling $^{2,3}$
}

Received: 27 June 2018/Accepted: 29 June 2018

(C) Springer Japan KK, part of Springer Nature 2018

\begin{abstract}
Transdisciplinarity is not a new science per se, but a new methodology for doing science with society. A particular challenge in doing science with society is the engagement with non-academic actors to enable joint problem formulation, analysis and transformation. How this is achieved differs between contexts. The premise of this paper is that transdisciplinary research (TDR) methodologies designed for developed world contexts cannot merely be replicated and transferred to developing world contexts. Thus a new approach is needed for conducting TDR in contexts characterised by high levels of complexity, conflict and social fluidity. To that end, this paper introduces a new approach to TDR titled emergent transdisciplinary design research (ETDR). A core element of this approach is that the research process is designed as it unfolds, that is, it transforms as it emerges from and within the fluid context. The ETDR outlined in this paper emerged through a case study in the informal settlement (slum) of Enkanini in Stellenbosch, South Africa. This case study demonstrates the context from and within which the ETDR approach and identifies a set of guiding logics that can be used to guide ETDR approaches in other contexts. The study demonstrates that the new logics and guiding principles were not simply derived from the TDR literature, but rather emerged from constant interacting dynamics between theory and practice. Learning how to co-design the research process through co-producing transformative knowledge and then implementing strategic interventions to bring about incremental social change is key to theory development in ways that are informed by local contextual dynamics. There are, however, risks when undertaking such TDR processes such as under-valuing disciplinary knowledge, transferring risks onto a society, and suppressing 'truth-to-power'.
\end{abstract}

Keywords Interdisciplinary research · Transdisciplinary research · Emergent design · Multi-track transdisciplinary processes $\cdot$ Boundary objects $\cdot$ Social transformation and innovation $\cdot$ Transformative knowledge co-production

Handled by Alexandros Gasparatos, University of Tokyo, Japan.

John van Breda

jrvb@sun.ac.za;

http://www.sun.ac.za/cst

Mark Swilling

swilling@sun.ac.za

1 Centre for Complex Systems in Transition, School of Public Leadership, Stellenbosch University Stias Stables, 19 Jonkershoekweg, Stellenbosch 7600, South Africa

2 School of Public Leadership, Stellenbosch University, Private Bag X1, Matieland 7602, South Africa

3 Sustainability Institute, Stellenbosch University, Lynedoch, 7603 Stellenbosch, South Africa

\section{Introduction}

Finding integrated sustainable solutions to the challenges that many African societies face today cannot be approached only from single disciplines. Mono-disciplinary analysis does not help us understand and grapple with emerging complex socio-ecological challenges. The application of single discipline knowledge produces partial solutions, but not the long-term, integrated and sustainable solutions needed.

An emerging body of literature argues that contemporary socio-ecological challenges warrant transdisciplinary responses that embrace what is referred to as knowledge co-production between science and society. This literally 
refers to a process that requires researchers to engage and collaborate with practitioners to co-generate knowledge to address problems that emerge in real-world situations. The concept of transdisciplinary research (TDR), which has emerged over the last two decades, is not a new science per se, but rather a new way of doing science, i.e., doing "science with society", rather than "science for society" (Becker 2012; Bergmann et al. 2013; Gibbons et al. 1994; Hadorn and Pohl 2008a; Jahn 2008; Jahn et al. 2012; Lang et al. 2012; Nowotny et al. 2001; Scholz 2011; Seidl et al. 2013).

Transdisciplinary research is not somehow 'new', as reflected in the literature cited in the preceding paragraph. It builds on a much longer tradition of 'interdisciplinary' research that has, in turn, spurned a backlash from within North American academia in "defense of disciplines" (see Jacobs 2013). More well known as "Mode 2" research (Gibbons et al. 1994; Nowotny et al. 2001) this tradition has always been interested in the social contextualisation of knowledge production (Rip 2011). The Max Planck Institute in Germany has since the 1970s sought to establish the socio-political determinants of knowledge power and the way 'scienticism' masks these knowledge-power relations (Bohme et al. 1973). More recently, in innovation studies, this kind of Mode 2 thinking has resulted in the more conservative literature on the dynamics of the "triple helix" between Universities, government and business (Etzkowitz and Leyesdorff 2000).

In the African context, Chilisa's seminal work has been making a case for integrating "indigenous knowledge" systems into a wider conception of "post-colonial research" (Chilisa 2011). In their introduction to a special Issue of "Interdisciplinary Science Reviews", Gross and Stauffacher (2014) reflect on this tradition to "problem-solving science" by examining the scientific oeuvre of Germany's largest research programme, namely the Helmhotz Association. Accepting that this field is maturing, they focus on how natural and social scientists collaborate to generate new empirical problem-solving research. In contrast to Gross and Stauffacher (2014) positive view of the maturing of this field, Jacobs (2013) views that this fashionable trend towards greater interdisciplinary and transdisciplinary research is in reality a false promise that could potentially undermine the scientific endeavour which has been so successful precisely because of the proliferation of disciplines. This critical perspective will be discussed further in the penultimate section of the paper. What matters for the purpose of this paper, is that except for few exceptions such as Chilisa (Chilisa 2011), Mode 2 research has emerged largely in the global North (Gibbons et al. 1994; Nowotny et al. 2001), where well-endowed research institutions can choose to engage with formalised, legitimate, and institutionalised stakeholders largely around the challenges of late industrial modernity.

A key challenge to successfully conduct "science with society" is to develop solution-oriented or transformative TDR approaches capable of not only explaining and understanding the complex societal challenges currently being faced in the world, but also of changing or transforming these challenges (Miller et al. 2014; Scholz 2011; Seidl et al. 2013; Stauffacher et al. 2006; Wiek and Lang 2016). However, how such transformative TDR approaches can be achieved differs considerably from context to context. This is because of the significant differences that exist, for example, between the social and material conditions of the developed and the developing world.

Developing transformative TDR approaches in and for developing world contexts, as in Africa, cannot be done on the basis of merely uncritically replicating and transferring the ideal-typical approaches developed in the developed world to the developing world. This is because such TDR approaches were conceived and implemented in and for a very different set of social and material conditions prevalent in the developed North. Some of the key academic institutions at the forefront of such TDR approaches include amongst others, the USYS TdLab (ETH, Zurich), the Institute for Socio-Ecological Research (ISOE, Frankfurt), and the Athena Institute (Free University of Amsterdam).

Although transformative in orientation, these textbook examples of TDR approaches seem to have in common the fundamental assumption that formal stakeholder engagement is the primary means of decision-making and communication. In other words such TDR approaches assume that certain social conditions are in place for this, where formal or legitimated societal stakeholders can engage on equal footing with scientists or experts from academia. In these contexts formal and highly institutionalised TDR processes seek to find real-world solutions to complex sustainability challenges (Scholz et al. 2009; Scholz 2011; Seidl et al. 2013; Stauffacher et al. 2006). However, the effect produced by this approach is the'foregrounding' and 'backgrounding' (Law 2004) of formality and informality, respectively.

However such characteristics are rarely encountered in different parts of the global South. There is now a substantial body of literature that has demonstrated how complex, heterogonous, hybridized and hodge-podged many urban systems in the global South, especially in Africa, have become In essence, unlike formalised regulated urban systems, space and time have not been transformed into predictable regulated routines of daily urban life in the 'untamed urbanisms' of the global South (Allen et al. 2015). This socio-cultural-economic heterogeneity has, in turn, resulted in diverse hybridized formal and 


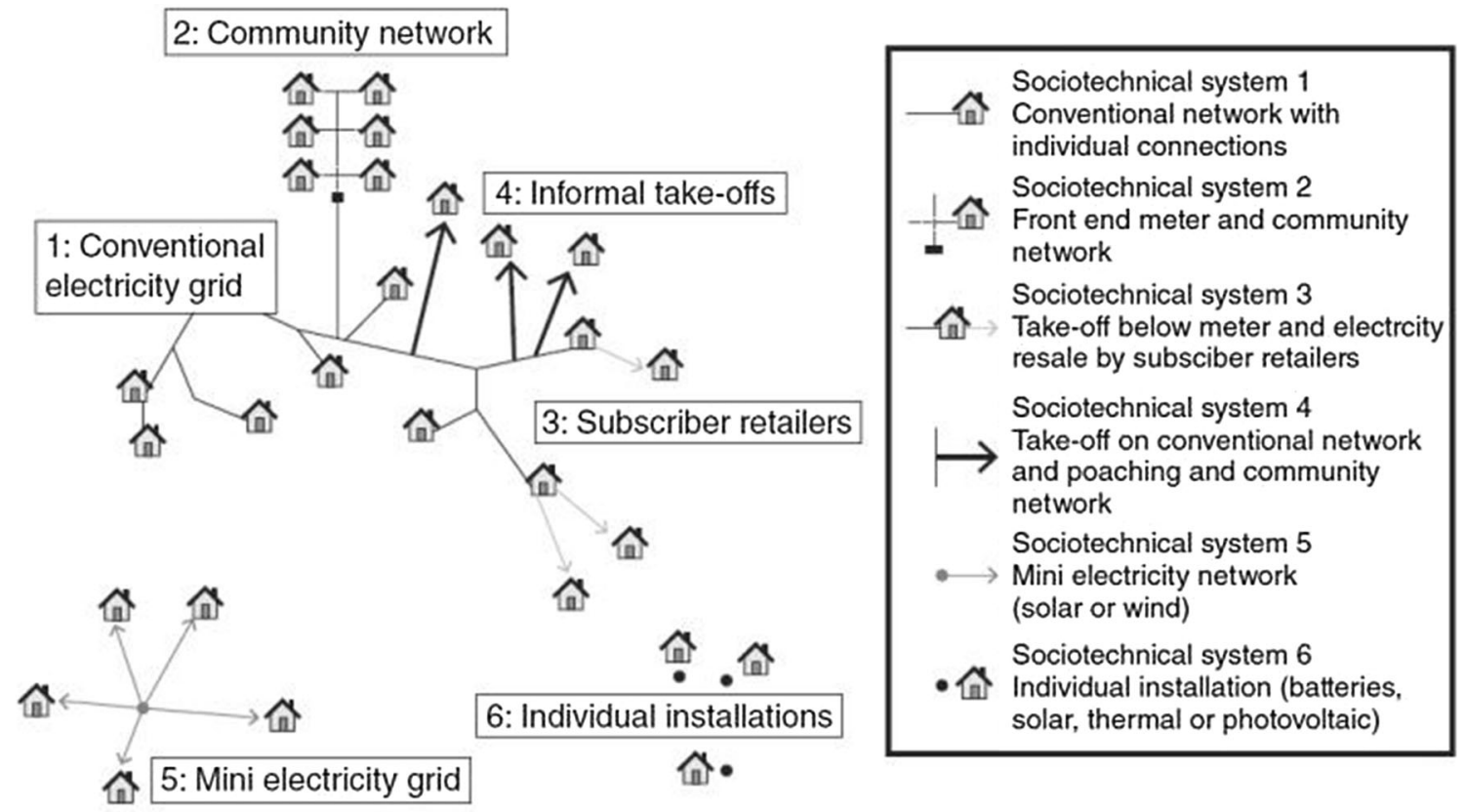

Fig. 1 Example of a delivery configuration related to household access to energy. (Source: Jaglin 2014)

informal service delivery systems that are appropriate for fast-changing, rapidly expanding, and inherently unstable urbanization processes (Allen et al. 2015; Edensor and Jayne 2012; McCarney and Stren 2003; Parnell and Oldfield 2014; Simone and Pieterse 2017; Simone 2004).

In this regard, Jaglin $(2014)^{1}$ develops a convincing argument that in cities of the global South service provision does not always reach the end user via the formal or conventional network. She concludes that "[I]n heterogeneous cities, the diversity of service needs has been a vector for innovation" (Jaglin 2014: 439). In other words urban experimentation in these contexts is not a marginal niche activity, but a defining feature of the way entire hybridized urban service delivery systems work in practice. Experimentation is implicit and emergent. It is not explicitly intentional and purposive as is the case in a fixed formal and well-regulated environment. This should not be however, comprehended with reference to the conventional universal service delivery model, nor is it a temporary step/ phase along a developmental pathway towards the final

\footnotetext{
1 According to Jaglin (2014: 438) service provision in southern cities is " a combination made up of a networked infrastructure, deficient in varying degrees and offering a rational service, and of private sector commercial initiatives, whether individual or collective, formal or informal, which are usually illegal in respect of the exclusive contracts of operators officially responsible for the service. These services fill the gaps in the conventional service and, depending on the type of urban area, target either the well-off clientele or poor clientele excluded from the main networks because of lack of resources, geographical remoteness or illegal status. These delivery configurations have one thing in common: the conventional network does not always reach the end user."
}

realization of this ideal. Instead, the various interconnected hybridized service delivery configurations are a totally different urban service delivery approach, which is here to stay in fast-growing complex heterogeneous cities and urban settlements of the global South (Allen et al. 2015; Edensor and Jayne 2012; McCarney and Stren 2003; Parnell and Oldfield 2014; Simone and Pieterse 2017; Simone 2004).For example, ever-changing interdependent sets of conventional, community-based, illegal and stand-alone non-grid systems are commonly encountered in urban energy sectors/systems of the global South (Fig. 1). In such systems the co-dependence of formal and informal systems within an evolving (and partially self-organising) experimental urbanism would be almost impossible to regulate, even if capacitated governance institutions were in place (Jaglin 2014).

Institutional hybridity is the logical response to this contextual heterogeneity. This hybridity is the emergent outcome of an endless multiplicity of experiments in daily life that constantly change and recompose (Allen et al. 2015; Edensor and Jayne 2012; McCarney and Stren 2003; Parnell and Oldfield 2014; Simone and Pieterse 2017; Simone 2004).

What has been productive about many instances of selfconstructed urbanisation is the experimental way in which the things that were built could be translated into each other in many different ways, i.e., what some have called urban assemblages (McFarlane 2011). Housing, work, sociability, caretaking, service provisioning, and livelihood were all connected to each other in ever-shifting assemblages. The character of the self-construction was a space 
where the many could become one, and the one many in a back and forth movement that ensured that there were a sufficient number of different ideas and ways of doing things. (Simone and Pieterse 2017). But at the same time, such differences did not rule out people paying attention to each other, and, as a result, making them an integral part of the stories they would weave out of their own lives (Simone and Pieterse 2017).

Considering the above, some communities in cities of the global South often have limited formal leadership to engage with, and mainly informal social actors and their equally informal social networks. Failing to recognise and work with the reality of informality on the ground will simply result in stasis, literally meaning that it is often impossible to get any form of transformative TDR process off the ground. Therefore, acknowledging and working with informality is a fundamental pre-condition for initiating and developing context-relevant transformative TDR approaches in developing world contexts. This is because the ability to engage with informal social-actor networks on the ground is as important, if not more, than setting up and dealing with formal stakeholder forums and processes.

It is against this background that this paper introduces Emergent Transdisciplinary Design Research (ETDR) using the case of the Enkanini informal settlement in Stellenbosch, South Africa. Based on a particular conception of the African urban challenge, we use the case of a solution-oriented transdisciplinary research in the Enkanini informal settlement to develop the ETDR approach. The Enkanini study is presented as a context-relevant approach for undertaking transformative transdisciplinary case study research in developing countries, which necessitates a different transdisciplinary research orientation and approach to those used in the global North. Overall, this paper integrates reflections on the outcome of a decadelong exploration of how to translate the transdisciplinary research approach into an African context, with special reference to the urban challenge in Africa. This research was coordinated by the Centre for Complex Systems in Transition in Stellenbosch University. A core element of this approach is that the research process is designed as it unfolds (Carew and Wickson 2010; Wickson et al. 2006), or to put it more poetically, through 'making the road by walking it' (Machado 2003; Machado and Trueblood 1982).

The primary aim of this paper is methodological, and in particular to make explicit as systematically as possible the logics and principles that emerged and guided the ETDR during the Enkanini transdisciplinary case study research (2011-2016). This paper, read together with the work by Chilisa (2011) cited above, should be read as a contribution to the discussion about how to operationalise transdisciplinary research in an African context. This paper is about what Mode 2 or transdisciplinary research means in a less formalised global South context where researchers may not be able to access institutionalised stakeholders to act as research partners. To be sure, it would have been very difficult, if not impossible, to have tried to do this research, with a TDR approach that only knows how to deal with formal legitimated stakeholder processes. Thus the selected TDR approach needs to acknowledge the extremely fluid situation of informal human settlements to make ends meet and escape the stronghold of endemic poverty, which is a daily struggle that is being played out in a complex network of informal social relationships and institutions.

\section{Methodology}

\section{Research approach}

In essence, the reported TDCS used a conceptual framework that drew from a diverse literature, including:

- complexity theory (Boulton et al. 2015; Cilliers 1998; Juarrero 2002; Mingers 2014; Snowden and Boone 2007; Vester 2007)

- emergent design theory (Cavallo 2000; Hasan 2006; Hesse-Biber 2010; Hesse-Biber and Leavy 2010; Jonas 2007; Sanders and Stappers 2008)

- assemblage theory (DeLanda 2006; Farías and Bender 2012; Harman 2008; Latour 2007; McFarlane 2011)

- learning theory (Argyris 2002; Kolb 2014; Medema et al. 2014; Corcoran and Wals 2012; Taylor and Cranton 2012; Tosey et al. 2012; Wals and Rodela 2014)

- narrative theory (Czarniawska 2004; Edelman 2006; Heinen and Sommer 2009; Kurtz 2014; Snowden 1999; Klein et al. 2011; Snowden 2010; Van Dijk 1976; Herman et al. 2010).

A key insight drawn from integrating this diverse body of literature for developing a context-sensitive transformative TDR approach is to link the notion of human agency in social-actor networks to the broader notion of complex systems change. In our understanding this means that, when complex systems change, social actors do not only make sense of what is happening in order to adapt, but they also, act to change their context. Context, therefore, matters (Latour 2007).

In our view, the existing literature on TDR has not as yet generated an adequate set of context-relevant guiding logics and principles. Without this there is no methodology that can be used for navigating transformative TDR processes in and under fluid social conditions like those 
observed and experienced in urban contexts of the global South. In this regard, as seen through the lens of the Enkanini case study, there are three problems that our research aims to respond to.

The first problem is that the existing principles for designing TDR tend to be too general and not sufficient for the purposes of dealing with the challenges of emergent design (see, Introduction), particularly when facing highly volatile circumstances in developing world contexts. This does not mean that there is anything 'wrong' per se with the design principles currently existing. It is rather a question of not going far enough in terms of actually anticipating and dealing with the reality of emergence. Such an example are the four principles of: (a) reducing complexity, (b) effectiveness through contextualisation, (c) integration through open encounters and (d) reflexivity through recursiveness (Hadorn and Pohl 2008b; Pohl and Hadorn 2007). It is not that these principles are completely without any merit, and that they should therefore be discarded. However, these principles are not in (and of) themselves adequate for designing and conducting emergent transformative TDR processes in and under the type of dynamic circumstances encountered in urban contexts of the global South such as Enkanini. For this, deriving a different set of guiding logics and principles is essential, and is thus the main focus of this paper.

The second problem relates to how TDR principles are formulated. This has two aspects. First is the static way in which certain principles have been formulated in more empirically oriented transdisciplinary case study research when dealing with real-world problems (e.g., large-scale industrial contamination). Second is the fundamental preconditions set for using and fulfilling these same principles. A case in point here is the following set of principles proposed by Foley et al.: (a) trust and willingness to collaborate (dealing with the problem of mistrust), (b) momentum (dealing with the problem of inertia), and (c) symmetrical power relations (dealing with the problem of power asymmetry) (Foley et al. 2017).

Related to the first aspect is the non-performative manner in which these principles have been formulated, since two of the principles are without any verbs. The purpose behind such principles is that they should be capable of igniting and guiding certain actions and decision-making, especially when working in and under the fluid social and material type of conditions as encountered in many contexts of the global South such as Enkanini. The way the above principles have been formulated (and presented here) certainly fall short of this performativity aspect of principles.

Related to the second aspect is the authors' perception that there is often a fundamental 'flaw' or 'mismatch' between the ideal and reality of multi-stakeholder TDR processes, primarily because of the exclusion of certain stakeholder groups. Consequently, the remedy proposed for overcoming this apparent disparity can only be achieved when there is absolutely no exclusion, and when all the relevant stakeholder groups have been treated 'equally' and 'fairly' in terms of all these principles (Foley et al. 2017). However, experiences and challenges from urban contexts of the global South can be very different to this normative approach, since it was more a case of pre-stakeholder engagement. In other words such cases reflect a situation of initiating a TDR process with no stakeholder groups within the community that could either be included or excluded (because there were none) in the TDR process. The TDR process in Enkanini had thus to be built on trust, willingness to work together and deal with huge social and educational inequalities on an individual shack-by-shack basis. In the face of this challenge, the TDR team felt that the existing TDR literature did not provide sufficient theoretical insights and guidance for the task at hand. We needed to draw on the different body of literature mentioned above which, upon critical reflection, resulted in the guiding logics and principles that resonated with the experiences of the researchers in the field.

The third problem has to do with the tendency of conflating the notions of methodology and methods. This seems to be prevalent in the more solution-oriented stream in the TDR literature (Bergmann et al. 2013; Miller et al. 2014; Scholz 2011; 2013; Stauffacher et al. 2006; Wiek and Lang 2016). By using these two concepts rather interchangeably this body of literature tends to reduce the discussion on methodology to a systematic analysis of a certain body of methods for doing solution-oriented TDR. In our view, this is done at the cost of giving sufficient attention to the development of principles necessary for designing and steering emergent transformative TDR processes.

To remedy this situation (and avoid any confusion at both the theoretical and practical levels) it is important to return to the original Greek etymology of the two notions of 'methodology' and 'methods'. Methodology, comprises of the three Greek words: 'meta' ( $\mu \varepsilon \tau \alpha$ ) signifying what is 'beyond' or 'above', 'hodos' (óós $\varsigma$ ) denoting a journey and 'logos' ( $\lambda$ ó $\left.{ }^{\circ} \varsigma\right)$. When put together it refers more broadly to the reasoning, logic or principles being used for tackling a sustainability challenge. The word methods, on the other hand, derives from only the two Greek words 'meta' and 'hodos', and omits the notion of 'logos'. This means that, although still performative in intent and purpose, methods have a more instrumental meaning because they are about acts of doing or performing certain techniques, steps or procedures when using certain tools and instruments for navigating a journey. However, methods on their own cannot tell us for what they are or should be used, or alternatively how they should be designed and used when 
tackling a sustainability challenge, particularly when the end state is not all that clear or when there are many different pathways of getting there. This, however, remains the role and function of the reasoning, logic and principles necessary not only for guiding the decision-making processes when tackling sustainability challenges, but, even more importantly, for informing the thinking and decisionmaking that needs go into designing the steps, procedures and tools needed for tackling sustainability challenges. This conceptual distinction between methodology and methods is reflected in the formulation of an appropriate set of logics and principles that both emerged and guided the research during the Enkanini TDCS.

It should be mentioned that that although the primary focus of this paper is establishing the guiding logics and principles of the ETDR approach, the actual Enkanini case study can serve to demonstrate the context from and within which the ETDR emerged. The context is critically important to demonstrate that the new guiding logics and principles were not derived solely from the literature, but emerged from the constant and critical exchange between theoretical reflection and on-the-ground experiences in the Enkanini context. This reflects the key tenets of the grounded theory. To this end, this paper adopts a single case study or idiographic approach (Gerring 2006; Krohn 2008; 2010; Yin 2009) as it allows for deeper immersion into a particular context. This enables the elicitation of indepth insights and understandings, not only of the social context, but also of the methodological logic and principles that emerged and guided the Enkanini transdisciplinary case study research process.

Finally, when working in a truly complex domain where non-linear cause-effect relationships and unforeseen consequences are the norm and researchers can never predict in advance whether their research will produce social change or transformative effects. (Juarrero 2002; Snowden 2005; Snowden and Boone 2007). Although this uncertainty or unpredictability poses many practical challenges for conducting and managing solution-oriented research processes, it is by no means an obstacle for gaining a deeper understanding of the causal dynamics of research cases embedded in a real-world context. On the contrary, making sense of and learning how to act in these emerging real-life situations in the present can be seen as the generator of critical reflection and theory-building. Thus the merger of research and innovation is the hallmark of idiographic cases (Krohn 2010).

\section{The Enkanini transdisciplinary research case study}

Enkanini (which means 'taken by force') is an informal (slum) settlement in Stellenbosch, South Africa. It was formed in 2006 when 47 families, who were renting backyard shacks in the neighbouring Kayamandi settlement, invaded the adjacent land owned by the Stellenbosch Municipality. By 2011, when the TDR projects reported in this paper began, about 1500 people occupied the settlement in about 400 shacks. By 2015, about 8000 people, that came from rural areas, surrounding farms and other urban settlements, lived in Enkanini in about 2000 shacks. The average age of residents is between 25-29 years, and nearly half of them are women (Wessels 2015).

The crux of the Enkanini case is the inadequate provision of infrastructure services (e.g., energy, sanitation, waste management) to this informal settlement by the local government. The problems that have arisen due to the lack of services include high levels of vermin (rats) invasions, indoor air pollution due to paraffin and candle use, frequent fires (111 fires in 2015), flash floods (840 since the establishment of Enkanini), and the associated increased health risks due to the above.

It could take up to 8 years for Stellenbosch municipality to rezone the land and formalise the settlement. Only when this process is complete would the municipality begin to consider installing formal services for all residents assuming the financial and human capital exists. Even so, the steep topography makes it difficult and expensive to build service-delivery infrastructure.

In the meantime, Enkanini residents began to organise themselves into informal structures to deal with the challenges of living in a completely under-serviced settlement. However, no single group had a mandate to speak for all residents of Enkanini. In fact, Enkanini has what are called unlegitimated stakeholders, which, in contrast to legitimate institutionalized stakeholders, are not recognized by the local and national government.

In 2011, the transdisciplinary research group based at Stellenbosch University approached individual residents within Enkanini with the idea of working jointly with residents to come up with solutions to the prevailing poor living conditions and lack of energy provision. The initial research aimed to answer what would the government's new policy of in situ upgrading of informal settlements mean in practice for the average resident of Enkanini. After many interviews with government officials and consultants it became clear that the answer to this question was 'wait' for the service delivery grids to arrive.

This generated what eventually became the primary research question: What can be done while people wait for this service to arrive? To address the wider range of issues that surfaced through this immersive process than originally anticipated (e.g., unsafe living conditions, lack of waste disposal infrastructure) the original research scope had to be expanded. 
Over the next 3 years, the TDR team in collaboration with a loose network Enkanini residents, designed and implemented three small-scale experiments in alternative service delivery:

- electricity (the iShack project);

- waste treatment (the Bokashi project);

- $\quad$ sanitation (the gravity-fed system project).

Under the leadership of Masters student Andreas Keller (Keller 2012), the iShack project started in 2011. It involved the co-design of an energy efficient shack, which used solar energy panels to generate enough power for two lights, an outside motion sensor and security light, and a cell phone charger. In 2012, the Gates Foundation funded the extension of the system to 100 households. This provided the basis for a successful application for funds from the South African Government's Green Fund (managed by the Development Bank of Southern Africa). At the time of writing (March 2018) there were more than a 1200 subscribers (out of 2000 shacks) paying R150 for the service per month. If they access the services just for lighting and a cell phone charger, they get the service for free, with the social enterprise compensated by a subsidy from the municipality. The municipality, in turn, agreed after a prolonged negotiation process to amend their policy so as to contribute a subsidy for the non-grid connected informal households that are part of the formal energy delivery system provided by the iShack. Local residents are trained to install and manage the iShack system, thus creating formal jobs for 6 people. Specialised Solar Systems, the company responsible for the technical design of the DCelectricity solar home units, were able to modify the design to enable the future switch over to AC-electricity systems (if necessary or desired). Subsequently, this South African company was replaced by B-Box, a UK company with extraordinary innovation capacity.

The second small-scale socio-technological experiment was the 'Bokashi' waste-treatment system project. Masters student Vanessa von der Heyde (von der Heyde 2014), one of the TDR team members, made contact with various disciplinary experts from the field of organic waste treatment, who in turn co-designed a context-relevant organic waste treatment system for small groups of Enkanini residents (up to 20 participating households). Households collected their organic household waste in buckets to which 'effective microorganisms' (Bokashi) were added and then dropped the buckets off at the local church. From there, the decomposed waste was used in local food gardens or sold to the Agriprotein project (which uses black soldier flies to process organic wastes) to produce animal and soil feed.

The third small-scale social experiment focused on sanitation. The 8000-odd Enkanini residents have to share
80 communal toilets. Besides the obvious sanitary implications, the lack of adequate facilities contributes to incidences of rape and assault. This immediate situation (a complex environment of immediacy) provoked the initiation of a dignified sustainable toilet system to manage solid waste. Under the leadership of $\mathrm{PhD}$ student Lorraine Ambole (Ambole 2016), the TDR team members responded to this need, and by following a deliberate co-designing approach they implemented a gravity-fed flush toilet sanitation intervention for 20 households. This small-scale social change experiment was divided into four groups of five shack-dwellers each, with each group connecting to an anaerobic biogas digester that used human excrement to produce gas for cooking purposes. Each household, in return, paid a small fee to cover the maintenance, repair and operating costs of the biogas digester.

\section{Results}

\section{Towards a guiding logics and principles of ETDR}

One of the main ripple outcomes of the Enkanini project has been a set of guiding logics and principles for conducting what we have named Emergent Transdisciplinary Design Research (ETDR). These guiding logics and principles should be seen as cognitive facilitators of imaginative and iterative decision-making processes. These processes are, by definition, incrementalist in that they tend to get driven forward by those who are best placed to ask "what is the next step' (Unger 1998; 2007) during the unfolding of the applied research processes. Rather than having to predict or know too far in advance exactly what the consequences of embarking on a particular vector or direction of change may be, it is strategically and practically more important to figure out the next step, and then see where that may lead to within a rapidly changing context. In other words, the guiding logics and principles of the ETDR approach presented below are not pre-determined or fixed principles, but rather are a more formal articulation of what emerged during the course of the Enkanini case study. Nevertheless, they may be useful for guiding the way ETDR case studies are conducted in future.

Figuring out the next research/implementation steps means imagining and creating spaces for the 'adjacent possible' (Snowden 2016; Unger 2007), 'in-between' or 'third-paces' (Vilsmaier and Lang 2015) where (radical) experimentation (Unger 1998; 2007; 2014) can be explored and promoted. This entails the consideration of many different social innovations and the implementation of new social institutions and socio-technical alternatives in contextually appropriate ways. 
Another way of putting it is that the guiding logics and principles create a cognitive framework for performing acts of 'side-casting' (Snowden 2012) rather than, by way of contrast, conducting the teleologically orientated 'forecasting' or 'back-casting' activities advocated in the transdisciplinarity literature (Scholz et al. 2006; Scholz 2011; Wiek and Lang 2016). Whether planning forwards, towards or backwards from the future, these teleological approaches have in common the fact that the present is always being approached from some or other idealised future imaginary, because of its very limited connectivity to the realities and complexities of the current situation. In the ETDR approach outlined in this paper, however, the role and function of the guiding logics and principles is to nudge the research process towards discovering the evolutionary potential of the present (Snowden 2015). In this sense, the present is not a burning platform between past and future, but rather where both meet in contested uncertainties expressed in both a multiplicity of experimentations and processes aimed at building up future imaginaries (Swilling et al. 2018 in press).

Overall, five basic principles guided the TDR process in an emergent and transformative direction: (a) perturbing the system, (b) innovating through exaptation, (c) multiloop learning, (d) allowing for emergence, and (e) absorbing complexity. These principles should be seen as the emergent outcome of an iterative process of critical reflection on a specific empirical research experience. As such, managed to perform the dual role of simultaneously emerging and guiding the research process as it unfolded.

\section{Perturbing the system}

The principle of "perturbing the system" comes from complex adaptive systems theory, which holds that systems are self-organizing and self-adapting. Small changes in one part of the system can effect bigger changes in other parts of the system, thereby making possible wider systemic change under certain conditions (Chu et al. 2003; Wright and Meadows 2012). Sometimes this change has to be kick-started by perturbing the system, pushing it into a state of dis-order that can be done consciously by using leverage. Indeed, while it is not possible to bring about total system change in complex contexts, it is possible to focus on strategic leverage points that catalyse change processes that evolve and expand over time (Meadows 1999; Wright and Meadows 2012). These processes usually consist of multiple, contextual, small-scale social experiments over a period of time (Snowden 2010; Snowden and Boone 2007). These small-scale or safe-to-fail social experiments (that might or might not work) are imagined as the co-construction of 'something' (Cavallo 2000) that acts as a 'boundary object' (Star 2010; Star and Griesemer
1989) or 'social attractor' (Snowden 2010). They are situated at the intersection of particular socio-technical and/or socio-ecological systems in need of broader systemic change. They are very different to large-scale (and usually high-risk) imposed 'real-world experiments'. ${ }^{2}$ This critical literature, discussed further in the penultimate section of the paper, warns that erasing the boundaries between science and society could result in serious harm to people and nature when 'real-world experiments' go wrong.

"Perturbing the system" in the Enkanini context means exploring and finding alternative, innovative means of bringing about social change. One such way could be through community representatives negotiating with government, (but this would assume that there is a readiness and willingness on both sides to enter into such a dialogue). In 2011 the Enkanini settlement was still illegal and there was no duly elected representative body with which to engage. According to Stellenbosch Municipality (SM), residents of Enkanini were not 'sufficiently mobilised' and therefore were not 'ready', as it were to be engaged with as stakeholders. In SM's view, Enkanini residents still had to be 'prepared' for such engagement. In this regard, the municipality involved Shack Dwellers International (SDI), an international NGO, to establish the exact number of residents and use this information to prioritise the basic needs of Enkanini residents.

The TDR team discussed the possibilities of joining and supporting the emerging SM-SDI stakeholder discussion forum, but decided against it as the research process could conceivably be locked into a 2-3-year process of formal institutionalised stakeholder engagement before generating any real-world solutions. In addition, the enumeration process (e.g., counting exercise of numbers of shacks, people, toilets, water taps) could itself exacerbate existing tensions. Instead, the TDR team searched for an appropriate research strategy with the understanding that any form of research conducted in a fluid social context, such as Enkanini, also had to be transformative. This also implied that the transdisciplinary research strategy would itself be emerging and participative to ensure that it was transformative. This strategy is distinctly different from traditional mono- and/or interdisciplinary approaches that most often formulate problem statements and research questions based only on the literature, in isolation with the tacit knowledge and real-life experiences of local communities (Mintzberg and Lampel 1999; Mintzberg et al. 2013; 1974).

There were two important consequences to this decision. First, the research team would need to focus on the

\footnotetext{
${ }^{2}$ Such high experiments have been discussed in the well-established literature that emerged after the Chernobyl disaster. For a review see Gross \& Hoffmann-Riem (2005).
} 
informal and individual relationships already formed in Enkanini; as opposed to conducting a formal stakeholder analysis to identify legitimated community leaders to collaborate with. Second, the research strategy would entail designing the small-scale, socio-technical innovations with individuals and small groups of shack dwellers. This strategy would make it possible for some residents to gain access to basic forms of electricity, waste and sanitation services during the research process. These three elements (i.e., working together in the present, with existing informal relationships, and generating workable innovations) became the crux of the research strategy, supporting the guiding principle of 'perturbing the system'.

It is worth mentioning that the shaping and implementation of this transformative research strategy in Enkanini took place in a high-risk and fluid social context. However, despite the risks involved in pursuing this transformative research strategy, the experience and knowledge gathered by the TDR team during their early visits to residents' homes (immersion) provided the subsequent (emergent) rationale and motivation for continuing with this approach.

There are now more than 1000 connected iShack systems in Enkanini, indicating that (a) the intervention has contributed significantly to social change, despite it not achieving 100 percent uptake, and (b) the TDR team certainly has 'earned' its place in any more formal decisionmaking regarding the future of the settlement. However, this is not to be regarded as a permanent or final 'solution' to the problems of the community. Instead, a collaborative effort that creates the foundations for further collaboration to continuously and incrementally improve living conditions in Enkanini, via experimentation, collective action and negotiation.

\section{Innovating through exaptation}

The combination of two fundamental principles "innovation" and "exaptation" (Snowden 2011), has played a key role in guiding the Enkanini TDR process-which meant going beyond 'bricolage' (Kincheloe and Berry 2004), merely using something what is at hand, but rather using the latter innovatively and creatively to serve different purposes and functions than originally intended.

Using this principle has meant working simultaneously with existing means and materials to solve existing problems, and using them as innovative solutions for new problems (exaptation). In turn, the process needed to demonstrate the possibility of unlocking the evolutionary potential of the present without having undertaken the traditional TDR practice of first establishing some normative ends (normally in the form of a shared vision and values) and then finding the most effective and efficient means with which to achieve these normative ends, and for co-designing and implementing provisional safe-to-fail experiments relatively quickly (Snowden 2010; 2011).

Despite not participating in the enumeration and stakeholder forum-building process driven by SM-SDI, the TDR team acknowledged that the SM-SDI approach intersected at various points with the TDR approach. This may be the start of a more formal dialogue process between the municipality and Enkanini residents. The TDR team posited that by focusing on implementing the iShack project, and achieving more than 1000 connections by 2016, it would have brought about a different set of social conditions. This would have enabled residents to engage with the municipality on a different level. Even if the DC-based iShack system is later connected to the state-supplied ACgrid, it is thought that the transformative social learning (discussed in more detail in 'Multi-loop learning' subsection below) that occurred during the project, and the experience of working together on basic service provision, will have brought about a change in how the municipality and residents interact in future negotiations.

Because the TDR literature does not provide guidance on how to implement TDR processes with informal, unlegitimated stakeholders, the research team had to seek theoretical guidance from literature focused on bottom-up approaches. To that end, useful concepts came from the peace-building and conflict resolution literature, in particular Track 1 and Track 2 negotiation processes (Diamond and McDonald 1996).

Track 1 approaches normally involve high-level government officials and leaders whose intent is to influence power structures and improve power relations so that negotiations and discourses can move forward. The downside of Track 1 approaches is that if power suppresses underlying issues, the sustainability of any agreements can be compromised (Mapendere 2005).

Track 2 approaches are not a replacement for Track 1, but rather a supplement to them. Their intent is to build relationships and encourage new thinking that can inform Track 1 negotiations. Often, Track 2 approaches are conducted via unofficial channels, and can precede official negotiations. In this sense they can lay the groundwork and establish a certain level of trust between partners, thereby de-escalating challenging situations. Essentially, Track 2 approaches build bridges, increase trust, correct misperceptions and unfounded fears, and mitigate dehumanization and entrenchment (Burgess and Burgess 1997). A downside to Track 2 is that participants rarely have the resources to implement any agreement. Sometimes, the two tracks occur simultaneously, called multi-track diplomacy (Burgess and Burgess 1997; Mapendere 2005; Snodderly 2011).

Track 2 peace-building or conflict resolution efforts are recognised for their affirmation that informal trust and relationships can contribute to finding and implementing 
durable solutions in the more formal Track 1 negotiation processes. These are normally conducted between legitimated decision-makers representing the interests of their constituencies/stakeholders (Davies and Kaufman 2003; Diamond and McDonald 1996; Esterhuyse 2012). This body of literature accepts that the connection and interaction between Track 2 and Track 1 approaches is fundamental. This is because without building trust and relationships as it happens in informal Track 2 processes, it becomes very difficult (even impossible), to reach and implement formal Track 1 negotiated agreements.

A Track 2 perspective made it possible to see a connection between initiating the Enkanini TDR process and contributing to a process of incremental social change. It became apparent that taking this informal route of building individual relationships of trust around the co-design and implementation of small-scale social experiments could potentially contribute to building a wider community culture of working together (Sennett 2012), and negotiating a better future with government.

While, the innovation/exaptation principle guided the TDR process, on reflection, the research process itself was contributing to a Track 2-type social change process. This was through embedding the TDR team within the Enkanini context, and linking it through informal relationships to residents and place.

\section{Multi-loop transformative learning}

The basic idea of "multi-loop learning" comes from Bateson (1972), namely that learning is an iterative process whereby people go through many loops of learning (see Fig. 2 for a graphic representation hereof). These comprise three distinct levels: "learn", "learn how to learn", and "learn how to learn how to learn". In particular:

- Level 1 signifies the acquisition of new technical knowledge and skills.

- Level 2 denotes the learning of learning, figuring out how to share and transfer newly acquired knowledge to others in order to do things more efficiently.

- Level 3 involves gaining critical awareness of the consequences and direction of the learning process and, consequently, the need for changing the underlying logic and principles driving the learning process. Transformative learning happens at this level.

Co-producing systems, target and transformation knowledge (Hadorn and Pohl 2008b; Pohl and Hadorn 2007) is fundamental to the ETDR approach and, in particular, the learning how to co-produce these three different types of knowledge in the fluid, emerging informal settlement context of Enkanini has been a major challenge. The underlying ideas on multi-loop learning were particularly useful (Bateson 1972; 2002; Medema et al. 2014; Tosey et al. 2012) in this regard of making sense of the continuous flow of experiences, reflections, ideas, theorising and actions in the context of Enkanini.

While all three levels of learning are necessary, transformative learning occurs at Level 3 as the deeper strategic insights and thinking into the learning process itself are generated. Level 3 learning goes beyond cognitive and intellectual skills as it involves the aesthetic and axiological aspects of learning as well.

In Enkanini, the TDR team started effectively with a first cycle of Level 3 learning by building relationships through painting shacks and staying over for weekends with individual shack dwellers (i.e., the aesthetic component of Level 3 learning). These activities focused specifically on establishing and building trust. The guiding problem statement of what could be done in the present while waiting for the state-funded grid solutions was both broad and specific enough to allow researchers to connect with individual families at the aesthetic level because people were already beautifying their shacks. This meant that the initial conversations taking place around shared activities of painting and preparing meals together in peoples' homes were more narrative-oriented in that researchers listened to real-life stories and histories; and observed first-hand the innovations people were undertaking to improve their current situation (innovation through exaptation, see above). It was the (learning) experience of a TDR member (Andreas Keller) living in a shack and experiencing the daily challenges faced by shack dwellers that gave rise to the real innovative idea of the iShack.

The insights gained from this first cycle of Level 3 transformative learning were critically important in cogenerating target and transformation knowledge. Through this process the TDR team could engage in developing and sustaining realistic expectations of what could be practically achieved in the present, as opposed to approaching the present from a normative and delayed point in the future, mediated by the interests of a distanced representative decision-making body operating from a distance. This learning "from" and "together" with the individuals in Enkanini had a significant impact on the co-generation of Level 1 and Level 2 learning, respectively.

The second cycle of transformative learning had its origins in the first cycle of Level 1 learning. This confirmed the entangled and interactive nature of the three levels (Tosey et al. 2012). It was during the process of co-designing, co-constructing and implementing the first few iShacks that it occurred to the TDR team that scaling up the initiative would entail going beyond the mere technical and technological aspects of recycled building materials, PVpanels and DC-electricity systems. New research questions 
Fig. 2 Bateson's levels of learning arranged as recursive hierarchy. (Source: Tosey et al. 2012)

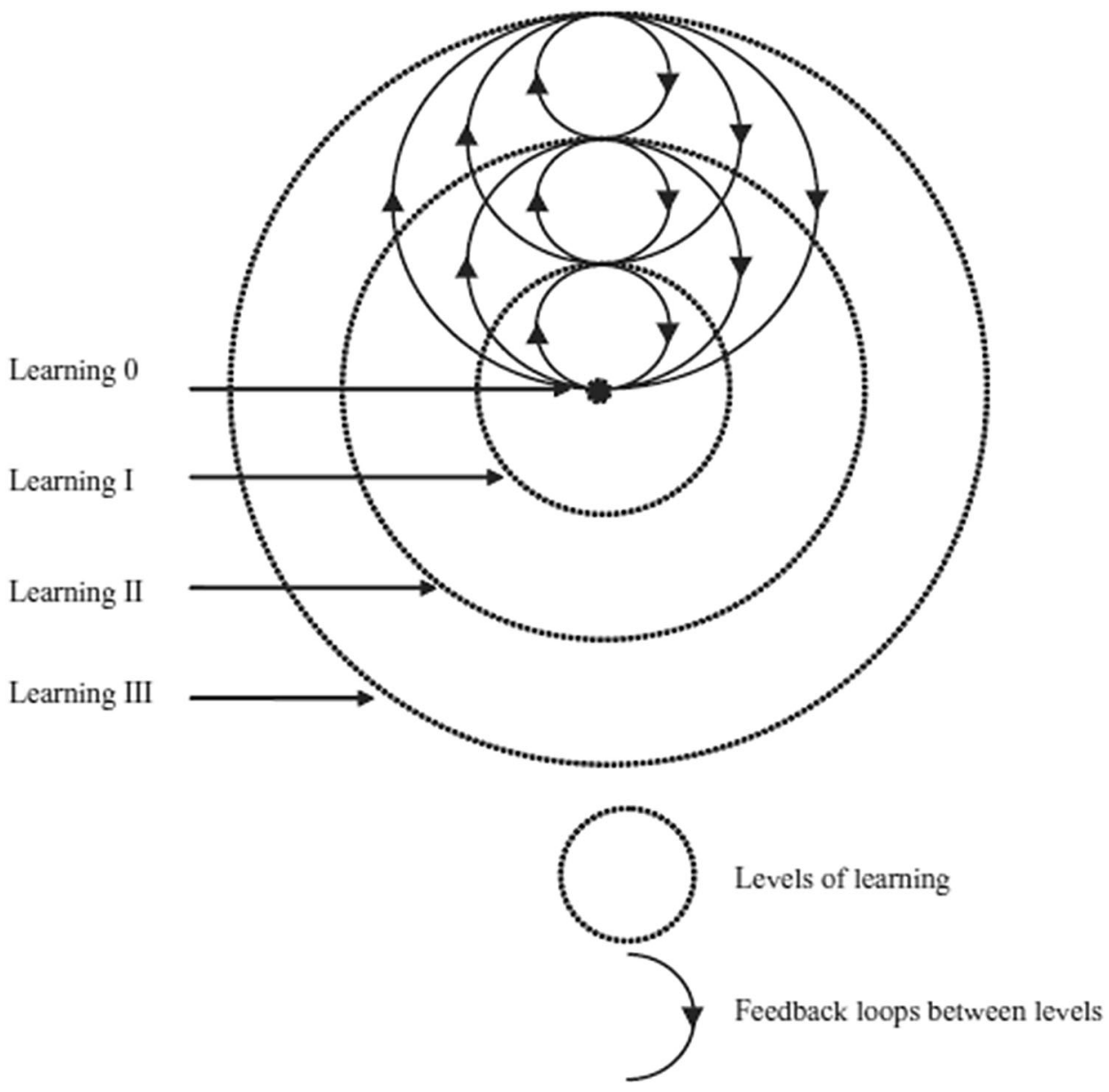

emerged as it became clear that, in the absence of state funding and support, the institutional arrangements for the payment and maintenance of the iShack system would have to come from the individual households themselves. Besides the apparently simple questions of whether people would be able and willing to pay for this, the more complex question arose as how to organise and institutionalise this in a social context that lacked a long and strong history of working together (Sennett 2012).

The institutional arrangements to maintain and collect payment for the system were co-designed with 20 shack dwellers connected to the iShack. This illustrated a second cycle of Level 3 learning, as it became apparent that what was being designed was an integrated socio-technical innovation. In other words, the design aesthetic was a bridging tool.

This Level 3 experience then sparked a second cycle of Level 1 and 3 learning related to how to integrate the social and technical aspects of the iShack system and how to replicate this socio-technical intervention in the rest of Enkanini among residents who chose to join on a voluntary basis.
In essence, this multi-loop learning process, which by no means proceeds in linear fashion from Level 1, to Level 2 and 3, produced the ideas (including the combination of renewable and sustainable technologies), the institutional arrangements, and the practices for paying for and maintaining the system. It is the real-life social laboratory of Enkanini that made this iterative and multi-level learning process possible.

\section{Anticipating and allowing for emergence}

The purpose of perturbing the system by implementing multiple safe-to-fail social experiments is to create the conditions necessary for longer-term solutions to emerge. It is critical to nudge the TDR research process to avoid premature convergence and enable emergence to occur (Snowden 2006; Snowden and Boone 2007; Snowden 2011).

The aforementioned leverage points are bifurcations, where a process can split in different directions and sites of instability, ripe with potential from which solutions can emerge. Transdisciplinary researchers must allow for solutions to begin morph into new entities, different to their 
original purpose(s) (in line with the principle of exaptation explained above). Transdisciplinary researchers must also remain open to taking advantage of convergent moments to source innovative funding options, necessitating thus adaptability, creativity, and intuition.

The guiding principle of 'allowing space for emergence' has three important aspects. First there is an expectation that the emergent property will be more than the sum total of its parts. In this case, more than the combined results of individual research activities and implementation of smallscale interventions. One such emergent property is a newly established culture of working together (Sennett 2012). ${ }^{3}$ Although it could be premature to label this phenomenon as an emergent property, new practices of working together are increasingly visible in the Enkanini settlement.

The TDR process has catalysed bringing together individual households in figuring out how to practically improve their current situation in the present, moving far beyond issues related to simply paying and maintaining the iShack, sanitation, and waste systems. What is particularly significant in the South African context is that this happened in the absence of any form of overt government administration. It could be argued that this would not have happened if only a top-down bureaucratic approach had been adopted in the form of a Track 1 multi-stakeholder approach (Burgess and Burgess 1997). Powerful stakeholders, such as government, normally want to 'own' and direct developmental processes, and so perpetuate or create unequal power relations.

The TDR process allowed for emergence, which meant that any practical ideas on what ought to be were worked during the co-design and implementation phases. A situational ethics was allowed to emerge through the situation of working together on what can be achieved in the presentand not some idealised and deferred point in the future. Situational ethics (contextualism) holds that each case is unique, meaning that ethical decisions should follow flexible guidelines rather than absolute rules or a priori principles, as per Kant's transcendental ethics (Kant 1996; 2005; 2012).

An illustration of this effect is that discussions and decision-making regarding the implementation of each of the three socio-technical innovations also entailed addressing the challenge of fairness. Each small group of shack dwellers had to anticipate the consequences of

\footnotetext{
3 By the time we approached the people of Enkanini in their informal social networks there had not been any shared experience amongst them of having worked jointly on any such project (e.g., electricity, water, waste). In other words, they were 'un-mobilised' following the NGO sector discourse. So, this 'culture' (or shared experience) of working together only emerged during our TDR process. As this was not something we intentionally planned for, it is reasonable to claim that it truly emerged during the TDR process.
}

potential default payees. These groups decided that households with genuine reasons would be given the opportunity to pay back arrears over a period of 36 months. But to guard against people who joined the system and then intentionally refused to make regular payments, the groups volunteered to establish savings accounts based on small, additional monthly payments to recoup losses in this regard.

A second important aspect for the ETDR approach is that having an idealised version of the future is not a fundamental prerequisite for initiating TDR processes. It is possible to start with practical, small-scale projects that aim to change the present and allow for normative discussions of the future to emerge from this process. For example in Enkanini we started with the iShack project and then slowly but surely introduced the Bokashi solid-waste and gravity-fed sanitation projects.

A third aspect was that by allowing for emergence implied that culture of working together which is at its infancy in Enkanini is not fixed or stable, so it cannot be taken for granted. The attempts to establish the necessary institutions to bolster a collaborative culture should therefore not be seen as a repetitive task, but rather as a task that which repeats itself until the next time, which is always the first time (Latour et al. 2012).

Trust is integral to building institutions and as it is not a tradable commodity. It is something that must be built, and rebuilt. This understanding has guided the work of the TDR team in taking on the challenge of connecting each group of shacks to the system, as if for the first time. The results are apparent in more than 1000 households connected to the system over the 4-year period, and the establishment of a socially-robust system, which has already stood the test of opposition from certain quarters in the settlement.

\section{Absorbing complexity}

It is better to use a research approach that "absorbs complexity" (i.e., make it work for you), rather than reducing it when working in complex, real-world contexts (Snowden 2011). Attempts to overly structure the research process to provide certainty in an uncertain environment are likely to lead to premature convergence and hasty conclusions. This requires researchers to retain some measure of cognitive agility and be open to the unanticipated.

In the fluid social conditions of Enkanini, it is not possible to accept the reduction of complexity (Pohl and Hadorn 2007) and the creation of conflict-free zones (Scholz 2011) as guiding principles for transdisciplinary research. The TDR research strategy encompassing perturbations of the system warrants an approach that "absorbs complexity" by finding ways of working with and around 
the power relations, which shape and are being shaped by the emerging community. It requires a two-pronged strategy of taking on powerful vested interests when required, and not engaging at other times.

Opposition to this TDR process did not only emanate from certain resident groups in Enkanini, but also from the municipality, as expressed in heated emails in 2011. All discussions and decisions made by the TDR team were done in conjunction with individuals representing their own interests and participating on a voluntary basis.

Taking this approach produced unexpected results. The municipality eventually endorsed the project by extending their indigent policy of basic free electricity to people offgrid that generate their own electricity. It also led to a group of residents actively mobilising against the project, as they felt it prevented them from gaining access to the municipal grid system. These unexpected (but unsurprising) responses added to the complexity of the unfolding situation, and demanded that the research team worked with complexity, as opposed to reducing it.

As articulated in the literature about absorbing complexity, the key to this approach is trust (Tait and Richardson 2010), which, in the context of Enkanini, must be seen as an emergent outcome of the entangled (Hodder 2012) social and technical relationships that were painstakingly assembled in and around all three small-scale safe-to-fail socio-technical innovations. Trust in the overall research project had to come from and be built both within and outside the TDR team. First and foremost, this trust had to be developed at the interpersonal level within the TDR team, having to learn to work together and trust each other's work. Secondly, trust within the team also had to be built in and around the renewable and sustainable technologies to be used in the three experimental projects. This was achieved synergistically through all the teambuilding activities that went into an iterative process of sourcing, testing, piloting, monitoring and evaluating the first smallscale versions of the iShack, Bokashi and gravity-fed sanitation systems.

As the research process unfolded, trust-building was achieved on a shack-by-shack basis, with every individual shack-dwelling family who voluntarily opted to participate in any one of the three small-scale projects. In short, in a fluid social context such as Enkanini, trust should not be seen and treated as a 'resource'. It is better to imagine it as an emergent outcome of the many entangled socio-technical relationships. Recognising this emergent character of trust certainly was key to navigating the dynamic and unequal power relations in the settlement as new stakeholder groupings emerged within the community. In doing so, learning how to absorb and work with complexity was ultimately more important than trying to reduce or minimise it.

\section{Discussion}

\section{Reflections from the Enkanini ETDR process}

The entire project described in this paper lasted between 2011 and 2016. Throughout its duration the TDR team had to learn how to deal with the emergence of unforeseen stakeholder alliances, both outside and within Enkanini. The responsiveness of the TDR team to prove that they were working on interim solutions, as opposed to imposing their own agenda on the settlement, gave further legitimation to the TDR process in the eyes of the community. This in turn, enabled the further roll-out of the TDR project.

As the project was an unfolding one, decisions were taken reflexively based on the contextual happenings in Enkanini. As a result it was not possible to know upfront how and what would need to be funded. The challenge of this type of research is therefore not restricted to matters of theory or navigating complex social and environmental contexts (as discussed above), but to a large degree depends on being able to fund interventions, change tasks quickly, and scale up or dampen the small-scale experiments as need arose. It thus became increasingly necessary to develop a practical and strategic intuition as to when to apply for funding and who to apply to. Sensing when to act upon converging moments, and how to turn these into opportunities to attract funders, has been fruitful to date. Most of the researchers involved in this TDR process have become invested in the project, and its unfolding process in ways that go beyond purely financial matters.

By seeing the research process as a discovery of the evolutionary potential of the present and experimental explorations in the in-between spaces adjacent to what already exists in the present, the ETDR approach takes a different route to other approaches in the teleologicallyoriented transdisciplinary literature. This teleological approach requires setting up purpose-constructed 'conflictfree zones' to conduct formal stakeholder engagement processes (Scholz et al. 2006; 2009; Scholz 2011). This amounts, in practice, to the creation of some protected communicative spaces within which rational-scientific discussions can take place between the participants. The purpose would then be to find the most efficient and effective means for achieving certain mutually-agreed upon ends.

The emergent kind of research process experienced and observed in the context of the Enkanini case needs some human energy for fuelling the imagination and experimentation (Unger 1998; 2007; 2014) with the real possibilities of the 'adjacent possible' in the 'in-between' spaces. This can be generated by the participants' 
conflicting needs and interests, values and norms, and experiences and perceptions. Learning how to work with the messiness of the current situation and harnessing this energy by figuring out how people are drawn and come together because of (rather in spite of or in the absence of) their differences, is critical for our methodological task of developing some appropriate guiding logics and principles of the ETDR approach. In this regard, it is important that these design principles are anticipatory both in their orientation and execution (Poli 2009; 2010a, b). In other words, these design principles must be capable of anticipating and working with uncertainty, emergence and unexpected circumstances, as and when it happens during the unfolding research process.

As already mentioned, when working in a truly complex environment of unknown unknowns, where non-linear cause-effect relationships and unforeseen consequences are the order of the day (Snowden 2005; Snowden and Boone 2007), it is not possible to predict in advance whether or what social change outcomes might come out of a particular research intervention. Needless to say that this is also true of any intentional transformative TDR intervention. The mere fact of engaging stakeholders is not an automatic guarantee that the decision-making and planning that normally happens in workshop settings will necessarily be translated into practical and sustainable solutions on the ground. This is especially true if these discussions have taken place only with the so-called "legitimated leaders" or representatives of the concerned groups, rather than the less formalised networks of concerned individuals. For this reason, the TDR team initiated the research process with no specific, pre-formulated, ideas on what specific type of social change should be expected from the specific research intervention. Of course, a range of known options came up during the discussions, ranging from state-driven upgrading of services to permanent neglect, with communitydriven incrementalism laying somewhere between these extremes. There were literally too many unknowns, particularly who and what was happening at the informal level of the Enkanini informal human settlement. Therefore, as already indicated above, the TDR team could only start the research process with a very open-minded transformative orientation. This was captured in the broad, research question of "what can be done incrementally in the present, whilst waiting for the Government to arrive with its more macro grid-solutions. To be sure, what exactly could be achieved in the present (given the social, material and geographical conditions and limitations of the Enkanini informal settlement), was not at all clear at the start of the process. It was only something that could be explored incrementally in the present, as the research process unfolded on a daily basis.
In such a volatile context what has been achieved today, can easily be overturned by a completely different set of circumstances and occurrences tomorrow. This only makes common sense that the transformative TDR process could not be designed and guided by an inductive or deductive hypothesis-proving or truth-seeking type of logic. This is because there are no hypotheses to be proven or disproven, even when it comes to what can or cannot be achieved with an incrementalism theory of social change. It was therefore clear from the onset that a very different type of explorative logic was needed for steering the research process incrementally in a broadly-speaking transformative direction, without having a clear-cut point of departure and point of arrival built into the transformative research process. It was in this context that the abductive logic became the driving logic of the TDR team. At first, it was used intuitively and subsequently, as the research process unfolded, more explicitly. As participating researchers started reflecting more critically on their research experiences and the type of reasoning informing their decisionmaking incrementally steered the research process in a transformative direction.

Turning to the literature on abductive logic intuitively also made a tremendous amount of sense, particularly upon (re)discovering the ground-breaking work of pragmatist philosopher C.S. Peirce (1974). This way of thinking has become known as the logic of hunches, of making connections between things on their plausibility (Snowden 2011). In this regard, what resonated strongly with both the experiences and reflections of the research team was the central notion that in the abductive mode of reasoning people "draw a (best guess) conclusion from an array of seemingly disparate and unconnected facts and observations" (Patokorpi 2006: 71). From this perspective of making connections and seeing patterns emerging in a context of disconnect and with no history or shared experience, coming and working together on any matters of concern in this particular settlement played a significant role in how the research team saw and understood the effects of their own research actions and how to plot the way forward (making the road by walking it). Particularly significant in this regard were the initial observations of some incremental changes in the patterns of the behaviours of the first individual shack-dwellers slowly but surelyfive households at a time-beginning to move in the direction of coming together to figuring out how the iShack system should be implemented, maintained and paid for.

In summary, the abductive logic was something that may be described as the emergent outcome of an iterative and reflexive process. This was between the practical experience of working in an explorative manner, on the one hand, and engaging critically with the relevant literature, on the other hand. It was not something that was taken from 
the literature and somehow applied to the practical situation of the Enkanini informal settlement. On the contrary, it was based on a more grounded theory or bottom-up way. At first, intuitively working in an abductive way by experimenting with a small-scale safe-to-fail (Snowden 2011) experiments in co-designing and building the first iShack and then observing changes in peoples' perceptions and behaviour in response to this, before moving on to building more iShacks and retrofitting existing shacks. It was only when some changes in perceptions and behaviour started to emerge that the critical engagement with and integration of the insights provided by the literature on abductive reasoning became really meaningful. This entailed the development of a deeper abductive understanding at the theoretical level of connections and insights from the experiences of Enkanini residents about the slowly expanding iShack system, and then feeding these insights back into plotting the next few steps of the unfolding research process. Continuously asking the question 'what are the next steps' (Unger 1998) became an important maxim of the research team capturing the abductive way of engaging with the individual shackdwellers in Enkanini. It also served as a continuous reminder to the research team that the TDR process was conducted in a context with no (facilitated) shared vision of the future from the residents of Enkanini. Rather it was a matter of working in the present and figuring things out as events unfolded. On critical reflection, it became increasingly clear that it would have been impossible to try and do this type of transformative transdisciplinary research with an inductive or deductive hypothesis-testing logic. This is because even the 'incrementalism' theory of change does not lend itself to hypothesis-building and testing, but rather favours experimentation as a means of uncovering alternatives that are very different to what can be found in a particular context (Unger 1998). Tentative conclusions could only be drawn in an abductive manner through the actual experiences gained from the processes of experimentation within the highly fluid social context of Enkanini.

\section{On the limits to transdisciplinary research and experimentation}

For those who are interested in exploring and applying transdisciplinary research approaches, there are three major criticisms that need to be acknowledged and addressed in some way: (a) what Jacobs (2013) calls the "anti-disciplinarity" of those who favour inter- or trans-disciplinary approaches; (b) the dangers of real-world experimentation in light of the precautionary principle; and (c), the muzzling of the critical role of science as the bearer of truth to power.
On anti-disicplinarity, Jacobs (2013) is correct in pointing that those who favour interdisciplinary research tend to undervalue disciplinary research. He contends that the interdisciplinarians have significantly over-stated the 'silo-isation' of disciplines, and largely ignored the noninstitutionalised manner in which disciplinary researchers actually collaborate in practice. Interdisciplinarians do this to justify the massive increase in funding for the institutionalisation of interdisciplinary research. However there might be a paradoxical situation of interdisciplinary specialisation expressed in the rise of a new generation of interdisciplinary institutions with specialist research agendas (Jacobs 2013). Instead of institutionalising interdisciplinarity, the disciplines should be reinforced and collaboration between disciplines incentivised. According to Jacobs (2013) the institutionalisation of interdisciplinarity, he argues, will result in the replication of the same problem that is seemingly being solved, i.e., excessive specialisation and competition between increasingly large specialised interdisciplinary programmes. However it should be pointed that Jacobs (2013) argument focuses on interdisciplinary research in North American contexts, and not on collaborations with society, which is what transdisciplinary research emphasizes. However, there cannot be inter- or trans-disciplinary research without strong basic disciplines. In the Enkanini case, researchers from different disciplines (e.g., architecture, engineering, ecological design, economics, finance and anthropology etc.) were intimately involved in the co-design of the three smallscale socio-technical experiments and found a way to collaborate based on mutual respect and a shared research methodology.

We should emphasize that the preamble to the Sustainable Development Goals (SDGs) calls for a "transformed world". In other words, there is widespread recognition that the polycrisis (Morin and Kern 1999) human societies face requires nothing less than a largescale structural transformation. However, when it comes to articulating a theory of change, the emphasis is on learning, dialogue, social innovation and experimentation rather than the state-centric seizures of power that preoccupied the revolutionaries of the 19th and 20th century. There is a widespread belief that science must support this theory of change, but as Gross and Hoffmann-Riem (2005) point out, there is a significant body of literature that strongly warns against a naïve attempt to erase the distinction between science and society in the name of social change. This practice goes against the precautionary principle and can disguise the process of transferring responsibility for serious risks from the scientists (who normally manage experiments in a laboratory), to society in general in topdown ways without ensuring that society is informed enough to make decisions about the associated risks. For 
Gross and Hoffmann-Riem (2005) the solution is to make sure that stakeholders are fully engaged in large-scale realworld experiments. In short, they fall back on processes we have pointed out as not always viable in many African urban contexts, but may well be needed. It might be better to accept that experimentation is going to perturb and fail, and that the resulting conflicts may well be how we learn and change from this failure. But this does not resolve the problem of the responsibility that science has for the experiments that it initiates within society.

Finally, during the course of the Enkanini case study it became clear that there is a price to be paid for collaborative work in unequal and conflict-ridden situations. In order to 'co-produce' productively problem-solving knowledge with stakeholders (including government agencies), it was no longer possible to openly criticize those responsible for reproducing injustice (including the Municipality and local politicians). What this implies is that research that depends on the facilitation of consensual problem-solving dialogue can result in the suppression of the traditional role of the critical researcher as talking 'truth-to-power' (Hadorn and Pohl 2008b). However, this is not a permanent condition, as after completion, the writeup of the research as a thesis and/or published article can, of course, include a critical analysis. However, the chances are high that this will trigger a negative reaction amongst stakeholders (if the material is actually read). Either way, social processes can become epistemologically constraint as to what can and cannot be articulated at different moments during the research process.

\section{Conclusion}

The ETDR approach illustrates what can be achieved at the practical, strategic and methodological levels of conducting contextual, and solution-orientated TDR. This approach makes a compelling case for the possibility of generating and steering the research process using guiding principles that emerge through the process itself via the reflexive and critical learning and the integration of various theoretical frameworks. This has implications for the methodological aspects of emergent TDR processes that need to navigate through the tricky terrain of practical and theoretical challenges.

This study further illustrates that it is possible to link transdisciplinary knowledge co-production to a process of incremental social change, in a way that not only interprets and explains context, but also, at times, contributes to changing it. It does this by following a Track 2 research strategy of focusing on the informal and what can be achieved in the present. By working at the micro-level, and by building individual epistemic relationships with individual social actors, the TDR team has facilitated a bottom-up process of connectivity. This has led to the emergence of small, collaborative networks or epistemic communities. These communities are, through the TDR process, empowered with practical knowledge that they can use to negotiate a better future for themselves.

The Enkanini TDR project has further demonstrated the appropriateness of incrementalism as a social change strategy in a fluid and complex environment, as it lends itself to integration with transformative (social change) research approaches. It is possible to bring about social change by creating an environment that is conducive for collaboration through connecting various research activities and innovations at the micro-level with individuals and networks. It is not the individual activities that lead to social change, rather, through the linkages created, something that is more than the sum of the parts emerges. This is illustrated by individuals recounting how they started to extend the connections made during the socio-technical interventions beyond these (and onto other) areas of immediate concern. Incremental social change also happens when the practical knowledge gained during the various socio-technical innovations is transferred to other areas and issues of the community, thus warranting different modes of collaboration.

ETDR is appropriate in contexts characterised by a combination of high levels of social inequality, fluidity, informality and experimentation as part and parcel of the fabric of social life. These conditions may very well be present in certain isolated pockets of society in the developed countries of the global North, but certainly not to the same extent or scale as is developing countries.

What emerged from this dynamic interchange between theory and praxis in the Enkanini case study has been a synthesis of the ideas, concepts, logics and principles found in complexity thinking, systems thinking, transformative learning, and assemblage and narrative theories. These informed the development of the guiding logics (abductive reasoning) and principles that have been discussed throughout this paper: (a) perturbing the system, (b) innovation through exaptation, (c) multi-loop learning, (d) allowing for emergence, and (e) absorbing complexity. At the same time we raise three fundamental critical questions about the entire endeavour of conceptualizing and implementing TDR approaches. These include the unproductive tendency to reduce the significance of disciplines, the dangers of unwittingly transferring responsibility for risk from the laboratory to society, and the ethical implications of compromising the obligation to talk 'truth-to-power' when faced with injustice.

In short, this is our best shot at making sense-both theoretically and practically —of our experience of experimenting with TDR in a particular context of an informal 
settlement in South Africa. We certainly hope to engage with others to deepen their and our praxis. In doing so, we would like to avoid the assumption that it is possible to arrive (either deductively or inductively) at a generic set of logics and principles applicable to all contexts. Rather, what would emerge is a body of concepts that can be drawn in different ways, depending on what researchers in different contexts may find useful to address in the questions that emerge from the vicissitudes of change.

In summary, any TDR process hoping to bring about social change in this dynamic environment simply has to acknowledge and work with what is happening on the ground. The methodological challenge is to come up with some guiding logics and principles capable of navigating transformative TDR processes. These processes are embedded in emergent contexts where informality is a stronger social force than what may pertain in most formal institutional engagements and decision-making processes that tend to be about the context in question rather than embedded within this context.

\section{References}

Allen A, Lampis A, Swilling M (2015) Untamed Urbanisms. Routledge

Ambole LA (2016) Understanding co-production through sanitation intervention case studies in South Africa (Thesis). Stellenbosch University, Stellenbosch

Argyris C (2002) Double-loop learning, teaching, and research. Acad Manag. Learn Educ. 1:206-218

Bateson G (1972) Steps to an ecology of mind: collected essays in anthropology, psychiatry, evolution, and epistemology. University of Chicago Press

Bateson G (2002) Mind and nature: a necessary unity. Hampton Press, Incorporated

Becker E (2012) Social-ecological systems as epistemic objects. In: Glaser M, Krause G, Ratter B, Welp M (eds) Human-Nature interactions in the anthropocene: potentials of social-ecological systems analysis. Routledge, London, pp 37-59

Bergmann M, Jahn T, Knobloch T, Krohn W, Pohl C, Schramm E (2013) Methods for Transdisciplinary Research: A Primer for Practice. Campus Verlag GmbH

Bohme G, Van den Daele W, Krohn W (1973) Die finalisierung der wissenschaft/the finalization of science. Z Für Soziol 2:128-144

Boulton JG, Allen PM, Bowman C (2015) Embracing Complexity: Strategic Perspectives for an Age of Turbulence. Oxford University Press

Burgess and Burgess (1997) Constructive confrontation: a Strategy for dealing with intractable environmental conflicts (WWW Document). Url http://www.colorado.edu/conflict/full_text_ search/AllCRCDocs/97-1.htm (accessed 5.23.16)

Carew AL, Wickson F (2010) The TD wheel: a heuristic to shape, support and evaluate transdisciplinary research. Futures 42:1146-1155

Cavallo D (2000) Emergent design and learning environments: building on indigenous knowledge. IBM Syst J 39:768-781

Chilisa B (2011) Indigenous research methodologies. SAGE
Chu D, Strand R, Fjelland R (2003) Theories of complexity. Complexity 8:19-30

Cilliers P (1998) Complexity and postmodernism: understanding complex systems. Routledge

Corcoran PB, Wals AEJ (eds) (2012) Learning for sustainability in times of accelerating change. Wageningen Academic Publishers

Czarniawska B (2004) Narratives in social science research. Sage

Davies JL, Kaufman E (2003) Second tract/citizens' diplomacy: concepts and techniques for conflict. Rowman \& Littlefield

DeLanda M (2006) A new philosophy of society: assemblage theory and social complexity. A\&C Black

Diamond L, McDonald JW (1996) Multi-track diplomacy: a systems approach to peace. Kumarian Press

Edelman GM (2006) Second nature: brain science and human knowledge. Yale University Press

Edensor T, Jayne M (2012) Urban theory beyond the west: a world of cities. Routledge

Esterhuyse W (2012) Endgame: secret talks and the end of apartheid. NB Publishers Limited

Etzkowitz H, Leydesdorff L (2000) The dynamics of innovation: from National Systems and "Mode 2" to a Triple Helix of universityindustry-government relations. Res Policy 29:109-123

Farías I, Bender T (2012) Urban assemblages: how actor-network theory changes urban studies. Routledge

Foley RW, Wiek A, Kay B, Rushforth R (2017) Ideal and reality of multi-stakeholder collaboration on sustainability problems: a case study on a large-scale industrial contamination in Phoenix, Arizona. Sustain. Science 12:123-136

Gerring J (2006) Case Study Research: Principles and Practices. Cambridge University Press

Gibbons M, Limoges C, Nowotny H, Schwartzman S, Scott P, Trow M (1994) The new production of knowledge: the dynamics of science and research in contemporary societies. SAGE

Gross M, Stauffacher M (2014) Transdisciplinary environmental science: problem-oriented projects and strategic research programs. Taylor \& Francis

Gross M, Hoffmann-Riem H (2005) Ecological restoration as a realworld experiment: designing robust implementation strategies in an urban environment. Public Underst Sci 14:269-284

Hadorn GH, Pohl C (2008a) Handbook of transdisciplinary research. Springer, Dordrecht

Hadorn GH, Pohl C (2008b) Handbook of transdisciplinary research. Springer, Dordrecht

Harman G (2008) DeLanda's ontology: assemblage and realism. Cont Philos Rev 41:367-383

Hasan H (2006) Design as research: emergent complex activity. Proceedings of the 17th Australasian Conference of Information Systems (ACIS 2006), Adelaide, 6-8 December 2006

Heinen S, Sommer R (2009) Narratology in the age of crossdisciplinary narrative research. Walter de Gruyter

Herman D, Jahn M, Ryan M-L (2010) Routledge encyclopedia of narrative theory. Routledge

Hesse-Biber SN (2010) Mixed Methods Research: Merging Theory with Practice. Guilford Press

Hesse-Biber SN, Leavy P (2010) Handbook of emergent methods. Guilford Press

Hodder I (2012) Entangled: an archaeology of the relationships between humans and things. Wiley

Jacobs JA (2013) In defense of disciplines: interdisciplinarity and specialization in the research university. University of Chicago Press

Jaglin S (2014) The routledge handbook on cities of the global south. Routledge

Jahn T (2008) Transdisciplinarity in the practice of research. Matthias bergmannengelbert schramm hg transdisziplinäre forsch. Integr. 
Forschungsprozesse Verstehen Bewerten, German (No English translation yet) $21-37$

Jahn T, Bergmann M, Keil F (2012) Transdisciplinarity: between mainstreaming and marginalization. Ecol Econ 79:1-10

Jonas W (2007) Design research and its meaning to the methodological development of the discipline. In: Michel R (ed) Design research now, board of international research in design. Birkhäuser, Basel, pp 187-206. https://doi.org/10.1007/978-37643-8472-2_11

Juarrero A (2002) Dynamics in action: intentional behavior as a complex system. MIT Press

Kant I (1996) Kant: The Metaphysics of Morals. Cambridge University Press

Kant I (2005) Groundwork for the metaphysics of morals. Broadview Press

Kant I (2012) Fundamental principles of the metaphysics of morals. Courier Corporation

Keller A (2012) Conceptualising a sustainable energy solution for in situ informal settlement upgrading (Thesis). Stellenbosch University, Stellenbosch

Kincheloe JL, Berry KS (2004) Rigour and complexity in educational research: conceptualizing the bricolage. McGraw-Hill International

Klein G, Snowden D, Pin CL (2011) Anticipatory thinking. In: Mosier KL, Fisch UM (eds) Information Knowledge, pp 235246

Kolb DA (2014) Experiential learning: experience as the source of learning and development. FT Press

Krohn W (2008) Learning from case studies. In: Handbook of Transdisciplinary Research. Springer, pp 369-383

Krohn W (2010) Interdisciplinary cases and disciplinary knowledge. Oxf. Handb. Interdiscip. Oxford University Press, New York, pp 32-49

Kurtz CF (2014) Working with stories in your community or organization: participatory narrative inquiry. On Demand Publishing, LLC-Create Space

Lang DJ, Wiek A, Bergmann M, Stauffacher M, Martens P, Moll P, Swilling M, Thomas CJ (2012) Transdisciplinary research in sustainability science: practice, principles, and challenges. Sustain Sci 7:25-43

Latour B (2007) Reassembling the social: an introduction to actornetwork-theory. OUP Oxford

Latour B, Jensen P, Venturini T, Grauwin S, Boullier D (2012) 'The whole is always smaller than its parts' - a digital test of Gabriel Tardes' monads. Br J Sociol 63:590-615. https://doi.org/10. 1111/j.1468-4446.2012.01428.x

Law J (2004) After method: mess in social science research. Routledge

Machado A (2003) There is no road. White Pine Press

Machado A, Trueblood AS (1982) Antonio Machado. Harvard University Press

Mapendere, 2005. Track one and a half diplomacy and the complementarity of tracks. COPOJ-culture of peace online journal. 2 (1). pp. 66-81-Google Scholar [WWW Document]. Url https:// scholar.google.co.za/scholar?q=Mapendere\%2C+J.+2005.+ Track + one + and $+\mathrm{a}+$ half + diplomacy + and + the + complemen tarity + of + tracks. + COPOJ +-+ Culture + of + Peace + Online + Journal $\% 2 \mathrm{C}+2 \% 281 \% 29 \% 2 \mathrm{C}+\mathrm{pp} .+66 \% \mathrm{E} 2 \% 80 \%$ 9381\&btnG $=\& \mathrm{hl}=$ en\&as_sdt $=0 \% 2 \mathrm{C} 5$ (accessed 5.23.16)

McCarney PL, Stren RE (2003) Governance on the ground: innovations and discontinuities in cities of the developing world. Woodrow Wilson Center Press

McFarlane C (2011) Learning the city: knowledge and translocal assemblage. Wiley

Meadows D (1999) Leverage points: place to intervene in a system. The Sustainability Institute: Hartland, VT, USA
Medema W, Wals A, Adamowski J (2014) Multi-loop social learning for sustainable land and water governance: towards a research agenda on the potential of virtual learning platforms. NJASWagening. J Life Sci 69:23-38

Miller TR, Wiek A, Sarewitz D, Robinson J, Olsson L, Kriebel D, Loorbach D (2014) The future of sustainability science: a solutions-oriented research agenda. Sustain Sci 9:239-246

Mingers J (2014) Philosophy and systems thinking: a mutual synergy. Routledge

Mintzberg H, Lampel J (1999) Reflecting on the strategy process. Sloan Manage Rev 40(3):21-30

Mintzberg H, Raisinghani D, Théoret A (1974) The Structure of "unstructured" Decision Processes. McGill University

Mintzberg H, Lampel J, Ghoshal S, Quinn JB (2013) The strategy process: concepts, contexts, cases. Pearson Education

Morin E, Kern AB (1999) Homeland earth: a manifesto for the new millennium. Hampton Press, Incorporated

Nowotny H, Scott P, Gibbons M (2001) Re-thinking science: knowledge and the public in an age of uncertainty. Wiley

Parnell S, Oldfield S (2014) The routledge handbook on cities of the global south. Routledge

Patokorpi, 2006. Role of abductive reasoning in digital interaction (Doctoral thesis, Åbo Akademi University, Finland). [WWW Document]. https://scholar.google.co.za/scholar?q=atokorpi\% $2 \mathrm{C}+$ E. $+2006 .+$ Role + of + abductive + reasoning + in + digi$\mathrm{tal}+$ interaction $+\% 28+$ Doctoral + thesis $\% 2 \mathrm{C}+\% \mathrm{C} 3 \% 85 \mathrm{bo}+$ Akademi $+\% 09$ University $\% 2 \mathrm{C}+$ Finland $\% 29 .+$ Available + at + http $\% 3 \mathrm{~A} \% 2 \mathrm{~F} \% 2 \mathrm{Fwww} . c s p e i r c e . c o m \% 2 \mathrm{Fmenu} \% 2 \mathrm{Flibrary}$ $\% 2$ Faboutcsp $\% 2$ Fpatokorpi $\% 2$ Fabduction.pdf $+\& b \operatorname{tnG}=\& \mathrm{hl}=$ en\&as_sdt $=0 \% 2 \mathrm{C} 5$. Accessed 23 May 2016

Peirce CS (1974) Collected papers of charles sanders peirce. Harvard University Press

Pohl C, Hadorn GH (2007) Principles for designing transdisciplinary research. Oekom, Munich

Poli R (2009) The complexity of anticipation. Balk J Philos 1:19-29

Poli R (2010a) The many aspects of anticipation. Foresight 12:7-17

Poli R (2010b) An introduction to the ontology of anticipation. Futures 42:769-776

Rip A (2011) The future of research universities. Prometheus 29:443453

Sanders EB-N, Stappers PJ (2008) Co-creation and the new landscapes of design. CoDesign 4:5-18. https://doi.org/10. 1080/15710880701875068

Scholz RW (2011) Environmental literacy in science and society: from knowledge to decisions. Cambridge University Press

Scholz RW, Lang DJ, Wiek A, Walter AI, Stauffacher M (2006) Transdisciplinary case studies as a means of sustainability learning: historical framework and theory. Int J Sustain High Educ 7:226-251. https://doi.org/10.1108/14676370610677829

Scholz RW, Spoerri A, Lang DJ (2009) Problem structuring for transitions: the case of Swiss waste management. Futures 41:171-181

Seidl R, Brand FS, Stauffacher M, Krütli P, Le QB, Spörri A, Meylan G, Moser C, González MB, Scholz RW (2013) Science with society in the anthropocene. Ambio 42:5-12. https://doi.org/10. 1007/s13280-012-0363-5

Sennett R (2012) Together: the rituals, pleasures and politics of cooperation. Penguin, UK

Simone A (2004) For the city yet to come: changing African life in four cities. Duke University Press

Simone A, Pieterse E (2017) New urban worlds: inhabiting dissonant times. Polity Press, London

Snodderly (2011) USIP "Peace Terms" Glossary [WWW Document]. U. S. Inst. Peace. Url http://www.usip.org/publications/usippeace-terms-glossary (accessed 5.23.16)

Snowden D (1999) Story telling: an old skill in a new context. Bus Inf Rev 16:30-37 
Snowden D (2005) Multi-ontology sense making: a new simplicity in decision making. J Innov Health Inform 13:45-53. https://doi. org/10.14236/jhi.v13i1.578

Snowden D (2006) Perspectives around emergent connectivity, sensemaking and asymmetric threat management. Public Money Manag 26:275-277

Snowden D (2010) Naturalizing Sensemaking. In: Mosier KL, Fischer UM (eds) Informed by knowledge: expert performance in complex situations. Taylor \& Francis, New York, pp 223 234

Snowden D (2011) Good fences make good neighbors. Inf Knowl Syst Manag 10:135-150

Snowden D (2012) Sidecasting techniques [WWW Document]. Cogn. Edge. URL/blog/sidecasting-techniques/(accessed 3.17.17)

Snowden D (2015) The evolutionary potential of the present [WWW Document]. Cogn. Edge. URL/blog/the-evolutionary-potentialof-the-present/(accessed 3.14.17)

Snowden D (2016) The adjacent possible [WWW Document]. Cogn. Edge. URL/blog/the-adjacent-possible/(accessed 3.14.17)

Snowden DJ, Boone ME (2007) A leader's framework for decision making. Harv Bus Rev 85:68. https://doi.org/10.14236/jhi.v13i1. 578

Star SL (2010) This is not a boundary object: reflections on the origin of a concept. Sci. Technol. Hum. Values 35:601-617

Star SL, Griesemer JR (1989) Institutional ecology, translations' and boundary objects: amateurs and professionals in Berkeley's Museum of Vertebrate Zoology, 1907-39. Soc Stud Sci 19:387420

Stauffacher M, Walter AI, Lang DJ, Wiek A, Scholz RW (2006) Learning to research environmental problems from a functional socio-cultural constructivism perspective: the transdisciplinary case study approach. Int J Sustain High Educ 7:252-275

Tait A, Richardson KA (2010) Complexity and knowledge management: understanding the role of knowledge in the management of social networks. IAP

Taylor EW, Cranton P (2012) The handbook of transformative learning: theory, research, and practice. Wiley
Tosey P, Visser M, Saunders MN (2012) The origins and conceptualizations of 'triple-loop' learning: A critical review. Manag Learn 43:291-307

Unger RM (1998) Democracy realized: the progressive alternative. Verso Unger RM (2007) The self awakened: pragmatism unbound. Harvard University Press

Unger RM (2014) What is Wrong with the Social Sciences Today? [WWW Document]. Url http://www.socialsciencespace.com/ 2014/01/roberto-mangabeira-unger-what-is-wrong-with-thesocial-sciences-today/ (accessed 7.25.16)

Van Dijk TA (1976) Philosophy of action and theory of narrative. Poetics 5:287-338. https://doi.org/10.1016/0304-422X(76)90014-0

Vester F (2007) The art of interconnected thinking: tools and concepts for a new approach to tackling complexity. MCB Verlag $\mathrm{GmbH}$, Munich, Germany

Vilsmaier U, Lang DJ (2015) Making a difference by marking the difference: constituting in-between spaces for sustainability learning. Curr Opin Environ Sustain 16:51-55

von der Heyde V (2014) Towards a sustainable incremental waste management system in Enkanini: a transdisciplinary case study (Thesis). Stellenbosch University, Stellenbosch

Wals AE, Rodela R (2014) Social learning towards sustainability: problematic, perspectives and promise. NJAS-Wagening. J Life Sci $69: 1-3$

Wessels BS (2015) MA-Thesis. Turning points: Exploring power transitions in an incremental upgrading process in Enkanin. Stellenbosch

Wickson F, Carew AL, Russell AW (2006) Transdisciplinary research: characteristics, quandaries and quality. Futures 38:1046-1059

Wiek A, Lang DJ (2016) Transformational sustainability research methodology. In: Heinrichs H, Martens P, Michelsen G, Wiek A (eds) Sustainability science - an introduction. Springer, Berlin, New York, pp 31-41

Wright D, Meadows DH (2012) Thinking in systems: a primer. Routledge

Yin RK (2009) Case study research: design and methods. SAGE Publications 